Etihad: Journal of Islamic Banking and Finance

Vol. 1, No. 2 Juli-Desember: 146-157

\title{
Faktor-Faktor yang Mempengaruhi Kepuasan dan Loyalitas Pengguna E-Channel pada Nasabah BSI KCP Ponorogo
}

\author{
Maulida Nurhidayati ${ }^{1 *}$, Novi Kurnia Cahyani ${ }^{2}$ \\ 1,2 Institut Agama Islam Negeri Ponorogo, Indonesia \\ Email: nurhidayati@iainponorogo.ac.id1, novikurnia12345@gmail.com2
}

\begin{abstract}
Technology that is growing rapidly penetrates all fields, including banking. Banking began to penetrate technology with the innovation of electronic channels or e-channels. Bank Syariah Indonesia KCP Ponorogo always strives to improve the ease and quality of service provided to increase customer satisfaction and loyalty. The results of interviews with customers showed that there are still customers who feel dissatisfied with e-channel provided by $\mathrm{BSI}$ and services that are still considered less than optimal which resulted in customers becoming dissatisfied and disloyal to BSI. This research aims to analyze the effect of ease and quality of service on customer satisfaction and loyalty and whether satisfaction can mediate the influence of ease and quality of service on customer loyalty. This research is a quantitative study with samples are BSI customers of e-channel users as many as 100 customers with sampling techniques are Incidental sampling. The data is collected by distributing questionnaires to a sample of 100 customers. The data is analyzed by the partial least square (PLS) method. The results showed that ease and quality of service affect customer satisfaction, ease has no effect on customer loyalty but the quality of service and customer satisfaction affect customer loyalty, In addition, customer satisfaction can mediate the influence of ease on customer loyalty and can mediate the influence of quality of service on customer loyalty. Based on these results, BSI can start improving the quality of existing services so that customer satisfaction and loyalty increase. In addition, there needs to be an easy guide to be followed by customers so that customers become active in using the e-channel facilities provided.
\end{abstract}

Keywords: Convenience; customer; loyalty; PLS; quality of service; satisfaction

Abstrak: Teknologi yang berkembang dengan pesat merambah semua bidang tidak terkecuali perbankan. Perbankan mulai merambah teknologi dengan adanya inovasi yaitu adanya electronic channel atau e-channel. Bank Syariah Indonesia KCP Ponorogo senantiasa berusaha meningkatkan kemudahan dan kualitas pelayanan yang diberikan untuk meningkatkan kepuasan dan loyalitas nasabah. Hasil wawancara dengan nasabah menunjukkan bahwa masih adanya nasabah yang merasa tidak puas dengan e-channel yang disediakan oleh BSI serta pelayanan yang masih dianggap kurang optimal hingga mengakibatkan nasabah menjadi tidak puas dan tidak loyal pada BSI. Penelitian ini bertujuan untuk menganalisis pengaruh kemudahan dan kualitas pelayanan terhadap kepuasan dan loyalitas nasabah serta apakah kepuasan mampu memediasi pengaruh kemudahan dan kualitas pelayanan terhadap loyalitas nasabah. Penelitian ini merupakan penelitian kuantitatif dengan sampel nasabah BSI pengguna e-channel sebanyak 100 nasabah dengan teknik pengambilam sampel Insidental sampling. Data dikumpulkan dengan menyebarkan angket kepada sampel 100 nasabah. Data dianalisis dengan metode partial least square (PLS). Hasil penelitian menunjukkan bahwa kemudahan dan kualitas pelayanan berpengaruh pada kepuasan nasabah, kemudahan tidak 
Etihad: Journal of Islamic Banking and Finance

Vol. 1, No. 2 Juli-Desember: 146-157

berpengaruh pada loyalitas nasabah akan tetapi kualitas pelayanan dan kepuasan nasabah berpengaruh pada loyalitas nasabah, Selain itu, kepuasan nasabah mampu memediasi pengaruh kemudahan terhadap loyalitas nasabah serta mampu memediasi pengaruh kualitas pelayanan terhadap loyalitas nasabah. Berdasarkan hasil ini pihak BSI dapat mulai meningkatkan kualitas pelayanan yang telah ada agar kepuasan dan loyalitas nasabah semakin meningkat. Selain itu perlu adanya panduan yang mudah untuk diikuti oleh nasabah agar nasabah menjadi aktif dalam menggunakan fasilitas e-channel yang disediakan.

Kata Kunci: kepuasan; kemudahan; kualitas pelayanan; nasabah; loyalitas; PLS

\section{PENDAHULUAN}

Saat ini PT Bank BRI Syariah menjadi bank syariah ketiga terbesar berdasarkan aset. PT Bank BRI Syariah tumbuh dengan pesat baik dari sisi aset, jumlah pembiayaan, dan perolehan dana pihak ketiga ("Profil dan Produk Bank BRI Syariah," 2015). Namun sekarang Bank BRI Syariah sudah resmi berganti nama menjadi Bank BSI yang merupakan hasil merger (penggabungan) dari tiga Bank BUMN, yaitu Bank BRI Syariah, Bank Syariah Mandiri, dan Bank BNI Syariah (Idhom, 2021). Dari sisi layanan, tidak ada perubahan mengenai sistem operasional dan layanan selama proses ini berlangsung. Bagi para nasabah, ketiga Bank tersebut akan menjamin sepenuhnya operasional tetap berjalan normal seperti dulu. Dari hasil pengamatan peneliti, loyalitas nasabah yang ada di BSI KCP Ponorogo Cokroaminoto bisa saja menurun dikarenakan beberapa faktor yaitu diantaranya kemudahan, kualitas pelayanan, dan kepuasan nasabah atau pelanggan.

Menjaga kepuasan dan loyalitas nasabah sangat penting karena sangat berpengaruh terhadap meningkatnya profitabilitas dari BSI. Loyalitas sendiri mengarah pada penggunaan secara berulang, merekomendasikan kepada orang lain, serta proporsi transaksi yang meningkat (Priansa, 2017). Menurut Kotler dan Keller, kepuasan mencerminkan penilaian yang diberikan seseorang dengan membandingkan kinerja suatu produk dengan harapan yang ingin dicapai (Kotler \& Keller, 2009). Pembelian seorang konsumen sangat dipengaruhi oleh faktor budaya, sosial, pribadi, dan psikologi. Pada faktor psikologi ini, pembelian seorang konsumen sangat dipengaruhi oleh motivasi, persepsi (persepsi kemudahan, persepsi resiko, dan persepsi manfaat), pembelajaran, kepercayaan, dan sikap. Menurut Fandy Tjiptono dan Gregorius Candara yang dikutip oleh Donni Juni Priansa, faktor yang mempengaruhi kepuasan yaitu produk, harga, promosi, lokasi, pelayanan karyawan, fasilitas serta suasana (Priansa, 2017).

Loyalitas didefinisikan sebagai komitmen yang dipegang seorang konsumen secara mendalam untuk membeli atau mendukung kembali produk dan jasa yang disukai dimasa yang akan datang meskipun terdapat kemungkinan adanya peralihan pelanggan akibat adanya pengaruh situasi maupun usaha pemasaran (Kotler \& Keller, 2009). Menurut Marconi, loyalitas dipengaruhi oleh nilai (harga dan kualitas), citra perusahaan, kenyamanan, dan kemudahan, kepuasan, kualitas pelayanan, serta garansi, dan jaminan yang diberikan oleh merek (Marconi, 1993). 
Etihad: Journal of Islamic Banking and Finance

Vol. 1, No. 2 Juli-Desember: 146-157

Bank Syariah Indonesia (BSI) KCP Ponorogo Cokroaminoto berada pada lokasi yang mudah dijangkau dan telah memberikan pelayanan dengan baik akan tetapi masih ada nasabah yang merasa tidak puas dan tidak loyal kepada Bank BSI KCP Ponorogo Cokroaminoto. Hal ini dapat diketahui karena masih ada nasabah yang tidak aktif menggunakan jasa layanan E-Channel (Devy, 2020). Rendahnya tingkat kepuasan dan loyalitas nasabah akan mengakibatkan menurunnya profitabilitas BSI. Pada penelitian ini difokuskan pada variabel kemudahan penggunaan e-channel dan kualitas pelayanan yang diduga dapat meningkatkan kepuasan dan loyalitas nasabah. Perceived Ease of Use (persepsi kemudahan penggunaan) didefinisikan sebagai sejauh mana konsumen mempercayai dengan menggunakan teknologi informs akan membebaskannya dari suatu usaha (Santi \& Sudiasmo, 2020). Kualitas pelayanan adalah suatu penilaian yang diberikan konsumen atas pelayanan yang diberikan pada produk atau jasa yang diterima oleh konsumen dengan tingkat pelayanan yang diinginkan atau diharapkan (Idrus, 2021).

Kemudahan penggunaan e-channel dan kualitas pelayanan mengakibatkan nasabah menjadi puas terhadap BSI dan mengakibatkan nasabah menjadi loyal terhadap BSI. Hasil wawancara dengan nasabah diketahui bahwa meskipun nasabah merasa puas dengan pelayanan yang diberikan. Mereka tidak bisa loyal karena beberapa alasan yaitu karena dorongan emosi dari nasabah serta karena pernah gagal dalam melakukan registrasi kartu pada pendaftaran awal, sehingga nasabah menjadi tidak aktif menggunakan e-channel yang memberikan akibat nasabah menjadi tidak loyal. Selain itu, ada juga nasabah yang merasa penggunaan layanan e-channel mudah dan tidak merasa adanya kendala dalam penggunaannya, namun akhirnya merasa tidak puas dan tidak loyal dikarenakan adanya keharusan untuk me-update aplikasi. Ada pula nasabah yang tidak loyal dikarenakan kegagalan dalam transaksi mengakibatkan saldonya berkurang.

Kepuasan dan loyalitas nasabah sangatlah penting bagi BSI karena mampu meningkatkan profitabilitas sehingga kepuasan dan loyalitas nasabah menjadi aset yang sangat berharga bagi BSI. Penelitian yang dilakukan oleh Arum Istiqomawati (2017), Kharisma Nawang Siqit \& Euis Soliha (2017), Hendri Wijaya dkk (2017) serta Anindita Imam Basri (2019) membahas tentang kepuasan dan loyalitas nasabah (Basri, 2019; Istiqomawati, 2017; Sigit \& Soliha, 2017; Wijaya, Beik, \& Sartono, 2017). Hal ini menunjukkan bahwa penelitian kepuasan dan loyalitas nasabah masih menarik untuk diteliti. Selain itu juga didukung oleh perbedaan hasil penelitian yang dilakukan oleh beberapa peneliti, seperti penelitian Evi Susanti dan Novita Oktavianti Parera yang menunjukkan bahwa kemudahan berpengaruh terhadap kepuasan dan loyalitas nasabah (Susanti \& Parera, 2021). Aprilinda, Mursyid, dan Sola menunjukkan ada pengaruh signifikan antara kualitas pelayanan terhadap loyalitas konsumen (Aprilinda, 2019; Mursyid, 2018; Sola, 2017). Sedangkan penelitian Pradana menunjukkan bahwa tidak ada pengaruh yang signifikan antara kualitas pelayanan terhadap loyalitas konsumen (Izzah \& Chasanah, 2020; Pradana, 2018). Dengan adanya ketidaksesuaian antara teori dengan praktik serta perbedaan hasil penelitian yang dilakukan oleh beberapa peneliti tersebut, maka perlu dilakukan analisis ulang mengenai kepuasan dan loyalitas nasabah. 
Etihad: Journal of Islamic Banking and Finance

Vol. 1, No. 2 Juli-Desember: 146-157

Adapun kebaruan penelitian ini adalah penggunaan Partial Least Square (PLS) untuk menganalisis hubungan antara masing-masing variabel serta menganalisis hubungan mediasi di dalam model. Selain itu, metode PLS tidak mensyaratkan data terdistribusi normal dan estimasi parameter dapat langsung dilakukan tanpa menggunakan persyaratan goodness of fit (Ghozali, 2021).

\section{TINJAUAN LITERATUR}

\section{Kepuasan}

Menurut Kotler dan Keller, kepuasan mencerminkan penilaian yang diberikan seseorang dengan membandingkan kinerja suatu produk dengan harapan yang ingin dicapai( Kotler \& Keller, 2009). Menurut Donni Juni Priansa, kepuasan konsumen merupakan suatu perasaan senang atau kecewa yang dimiliki konsumen setelah konsumen membandingkan kenyataan yang diperoleh dengan harapan yang ingin dicapai oleh konsumen (Priansa, 2017).

Harapan konsumen adalah perkiraan atau keyakinan konsumen terhadap segala sesuatu yang diterima apabila konsumen membeli atau mengkonsumsi suatu barang dan jasa (Fandi Tjiptono, 2002). Jika suatu produk tidak memenuhi harapan, maka konsumen akan merasa tidak puas dan kecewa. Sedangkan jika suatu produk memenuhi harapan, maka konsumen akan merasa puas. Jika kinerja dari suatu produk melebihi harapan, maka konsumen akan merasa senang (Kotler \& Keller, 2009). Berdasarkan hal tersebut, dalam menentukan harapan yang tepat, maka seorang pemasar harus melakukannya dengan hatihati. Hal ini akan berakibat pada sedikit atau banyaknya konsumen yang tertarik (Kotler \& Amstrong, 2012). Menurut Donni Juni Priansa, kepuasan konsumen memiliki beberapa manfaat yaitu reaksi terhadap prosuder berbiaya rendah, manfaat ekonomik retensi konsumen terhadap perceptual prospecting, nilai kumulatif dari relasi berkelanjutan, daya persuasive word of mounth, reduksi sensitivitas harga serta kepuasan konsumen yang merupakan indikator kesuksesan bisnis di masa depan (Priansa, 2017).

\section{Loyalitas}

Menurut Kotler dan Keller, loyalitas didefinisikan sebagai komitmen yang dipegang seorang konsumen secara mendalam untuk membeli atau mendukung kembali produk dan jasa yang disukai di masa yang akan datang, meskipun terdapat kemungkinan adanya peralihan pelanggan akibat adanya pengaruh situasi maupun usaha pemasaran (Kotler \& Keller, 2009). Loyalitas konsumen merupakan komitmen konsumen pada jangka panjang yang terwujud dalam perilaku dan sikap yang loyal terhadap perusahaan serta produknya. Loyalitas mengindikasikan bahwa konsumen melakukan konsumsi secara teratur dan berulang yang mengakibatkan perusahaan dan produknya menjadi bagian yang penting dari proses konsumen yang dilakukan oleh konsumen (Priansa, 2017).

Konsumen yang loyal adalah aset yang sangat penting bagi perusahaan. Karakteristik dari loyalitas konsumen menurut Griffin yang dikutip oleh Donni Juni Priansa yaitu melakukan pembelian secara teratur, membeli diluar lini produk/jasa, merekomendasikan produk lain, 
Etihad: Journal of Islamic Banking and Finance

Vol. 1, No. 2 Juli-Desember: 146-157

serta menunjukkan kekebalan dari daya Tarik produk sejenis dari pesaing (Priansa, 2017). Hubungan antara kepuasan dan loyalitas konsumen tidak proporsional. Konsumen yang mempunyai kepuasan yang tinggi biasanya memiliki kesetiaan lebih lama, melakukan pembelian lebih banyak ketika perusahaan memperkenalkan produk baru atau memperbaharui produk yang ada, jarang memperhatikan merek pesaing dan tidak sensitif terhadap harga (Priansa, 2017).

\section{Kemudahan Penggunaan}

Menurut Jogiyanto yang dikutip oleh Indyah Hartami Santi dan Bayu Erdani, Persepsi kemudahan penggunaan didefinisikan sebagai sejauh mana seorang konsumen percaya bahwa menggunakan suatu teknologi akan bebas dari usaha. Jika konsumen merasa percaya bahwa sistem informasi mudah digunakan, maka konsumen akan menggunakannya. Namun jika seseorang merasa tidak percaya dengan sistem informasi, maka pengguna tidak akan menggunakannya (Santi \& Erdani, 2021). Perceived Ease of Use (persepsi kemudahan penggunaan) didefinisikan sebagai sejauh mana konsumen mempercayai dengan menggunakan teknologi informs akan membebaskannya dari suatu usaha (Santi \& Sudiasmo, 2020).

\section{Kualitas Pelayanan}

Kualitas pelayanan adalah suatu penilaian yang diberikan konsumen atas pelayanan yang diberikan pada produk atau jasa yang diterima oleh konsumen dengan tingkat pelayanan yang diinginkan atau diharapkan. Kualitas pelayanan bagi produsen merupakan spesifikasi produk atau jasa yang dirancang dan disesuaikan dengan apa yang dibutuhkan atau yang diinginkan oleh konsumen (Idrus, 2021). Kualitas pelayanan mempunyai hubungan yang erat dengan kepuasan konsumen. Kualitas pelayanan mampu memberikan dorongan kepada konsumen untuk dapat menjalin ikatan hubungan yang kuat dengan perusahaan. Dalam jangka panjang, hubungan ini memungkinkan perusahaan untuk memahami dengan seksama harapan konsumen serta kebutuhan dari konsumen tersebut (Fandi Tjiptono, 2002).

\section{METODE PENELITIAN}

Pendekatan yang digunakan dalam penelitian ini adalah penelitian lapangan dengan pendekatan kuantitatif, di mana pada pendekatan ini, hubungan antara variabel dianalisis dengan menggunakan teori yang objektif (Sujarweni, 2015). Variabel terbagi menjadi variabel bebas (kemudahan dan kualitas pelayanan), variabel mediasi (kepuasan nasabah), dan variabel terikat (loyalitas nasabah). Jumlah sampel yang terlibat pada penelitian ini adalah 100 orang yang merupakan nasabah BSI KCP Ponorogo yang menggunakan e-channel. Teknik sampling yang digunakan adalah insidental sampling.

Metode pengumpulan data dilakukan dengan menggunakan kuesioner. Kuesioner disusun dengan menggunakan kisi-kisi instrumen pada tabel 1 dengan skala pengukuran dengan menggunakan lims respon jawaban. Kuesioner yang dibuat selanjutnya diuji terbatas 
Etihad: Journal of Islamic Banking and Finance

Vol. 1, No. 2 Juli-Desember: 146-157

kepada 30 orang untuk menguji validitas dan reliabilitas dari kuesioner tersebut. Kuesioner yang telah valid dan reliabel selanjutnya dijadikan sebagai kuesioner penelitian. Data yang diperoleh dari angket penelitian tersebut selanjutnya dianalisis dengan metode Partial Least Square (PLS).

Tabel 1. Kisi-kisi Instrumen Masing-masing Variabel

\begin{tabular}{ll}
\hline \multicolumn{1}{c}{ Variabel } & \multicolumn{1}{c}{ Indikator } \\
\hline Kemudahan $\left(\mathrm{X}_{1}\right)$ & a. Efisiensi waktu \\
& b. Kemampuan melakukan transaksi \\
& $\begin{array}{l}\text { c. Kemudahan operasional } \\
\text { d. Penggunaan yang fleksibel }\end{array}$ \\
\hline Kualitas Pelayanan ( $\left.\mathrm{X}_{2}\right)$ & a. Keandalan \\
& b. Ketanggapan \\
& c. bukti fisik \\
& d. jaminan dan kepastian \\
& e. perhatian \\
\hline Kepuasan Nasabah (Z) & a. Kualitas produk \\
& b. Kualitas pelayanan \\
& c. Emosional konsumen \\
& d. Harga \\
& e. Biaya konsumen \\
\hline Loyalitas Nasabah (Y) & a. Melakukan pembelian ulang secara teratur \\
& b. Menciptakan citra positif dari mulut ke mulut \\
& c. Komitmen merek \\
\hline
\end{tabular}

\section{HASIL DAN PEMBAHASAN}

Kuesioner yang telah disusun disebarkan secara terbatas kepada 30 orang untuk selanjutnya diuji validitas dan reliabilitas. Hasil pengujian menunjukkan bahwa kuesioner yang disusun telah memenuhi uji validitas dan reliabilitas karena semua item pernyataan yang

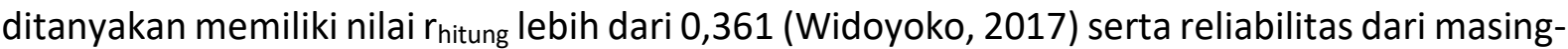
masing variabel lebih dari 0,7(Widoyoko, 2017). Karena kuesioner telah memenuhi pengujian validitas dan reliabilitas, maka kuesioner ini dapat digunakan untuk mengumpulkan data penelitian. Karakteristik responden ditunjukkan pada gambar 1, gambar 2, dan tabel 2. 
Etihad: Journal of Islamic Banking and Finance

Vol. 1, No. 2 Juli-Desember: 146-157

Gambar 1. Identifikasi Responden Berdasarkan Kelamin dan Usia

\section{Jenis Kelamin}

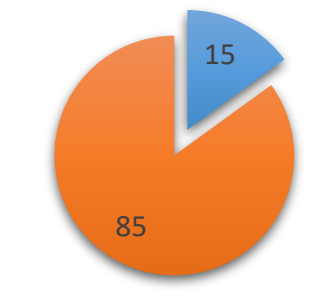

- Laki-laki Perempuan

\section{Usia}

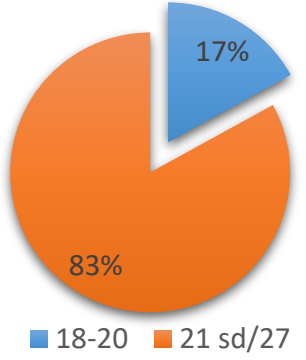

Gambar 2. Identifikasi Responden Berdasarkan Pekerjaan

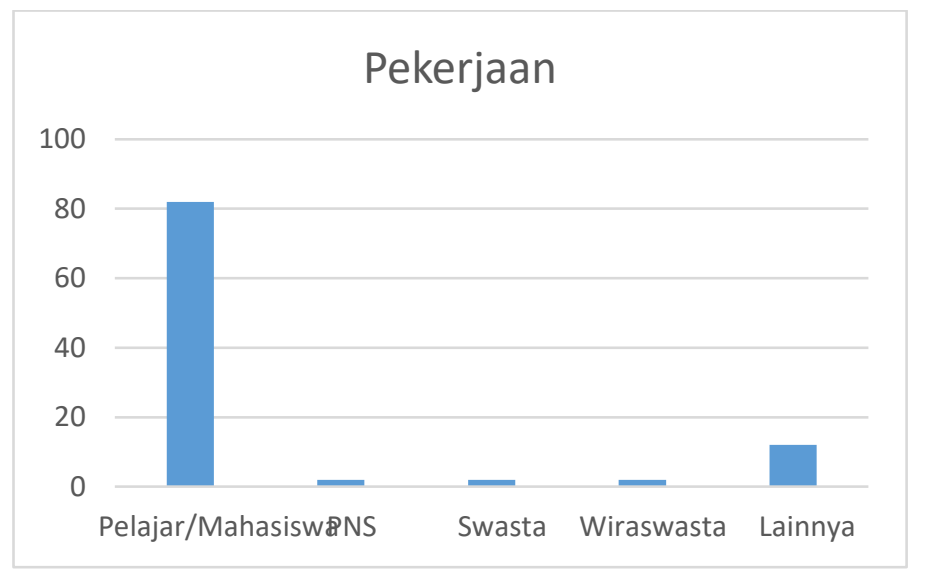

Gambar 3. Loading Factor Model Pertama

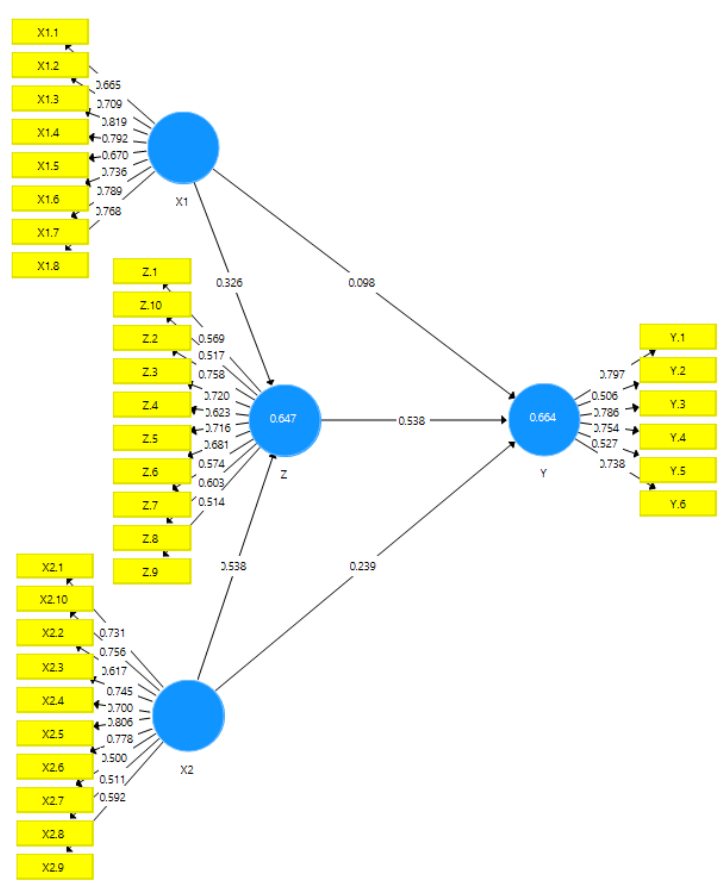


Etihad: Journal of Islamic Banking and Finance

Vol. 1, No. 2 Juli-Desember: 146-157

Gambar 1 memperlihatkan bahwa responden penelitian ini didominasi oleh perempuan dengan jumlah 85 orang. Gambar 1 dan Gambar 2 menunjukkan bahwa usia responden 18-20 mendominasi responden penelitian dengan pekerjaan sebagai pelajar/mahasiswa.

Gambar 3 menunjukkan bahwa model pertama memiliki sembilan item pernyataan dengan nilai loading factor di bawah 0,6 . Item pernyataan tersebut adalah $\mathrm{X}_{2.7}, \mathrm{X}_{2.8}, \mathrm{X}_{2.9}, \mathrm{Z}_{1}, \mathrm{Z}_{4}$, $Z_{9}, Z_{10}, Y_{2}$ dan $Y_{5}$. Kesembilan item pernyataan dikeluarkan dari model. Model yang baru selanjutnya dieksekusi dan diperoleh loading factor pada Tabel 2. Hasil estimasi outer model koreksi pada menunjukkan bahwa semua item pada setiap variabel memiliki loading factor diatas 0,6 (Ghozali, 2014; Widarjono, 2015) sehingga variabel kemudahan, kualitas pelayanan, kepuasan nasabah, dan loyalitas nasabah memenuhi validitas konvergen.

Tabel 2. Hasil Evaluasi Validitas Diskriminan

\begin{tabular}{lllrr}
\hline & $X_{1}$ & $X_{2}$ & $Y$ & $Z$ \\
\hline$X_{1}$ & 0,745 & & & \\
\hline$X_{2}$ & 0,684 & 0,763 & & \\
\hline$Y$ & 0,618 & 0,712 & 0,804 & \\
\hline$Z$ & 0,652 & 0,714 & 0,72 & 0,725 \\
\hline
\end{tabular}

Tabel 3. Hasil Uji Reliabilitas Komposit

\begin{tabular}{lr}
\hline & Composite Reliability \\
\hline$X 1$ & 0,908 \\
\hline$X 2$ & 0,906 \\
\hline$Y$ & 0,88 \\
\hline$Z$ & 0,868 \\
\hline
\end{tabular}

Tabel 4. Koefisien Jalur

\begin{tabular}{ccc}
\hline & Original Sample (O) & P Values \\
\hline$X_{1} \rightarrow Y$ & 0,127 & 0,264 \\
\hline$X_{1}->$ & 0,309 & 0,000 \\
\hline$X_{2}-Y$ & 0,347 & 0,003 \\
\hline$X_{2}->$ & 0,503 & 0,000 \\
\hline$Z->Y$ & 0,389 & 0,000
\end{tabular}

Tabel 2 memperlihatkan bahwa nilai akar AVE variabel $X_{1}$ adalah 0,745; variabel $\mathrm{X}_{2}$ adalah 0,763; variabel $\mathrm{Y}$ adalah 0,804 dan variabel $\mathrm{Z}$ adalah 0,725 . Nilai akar AVE ini lebih besar dari pada nilai korelasi antar variabel. Hal ini mengindikasikan model memenuhi validitas diskriminan. Tabel 3 memperlihatkan nilai reliabilitas komposit dari variabel $X_{1}$ adalah 0,908 ; variabel $X_{2}$ adalah 0,906 ; variabel $Y$ adalah 0,880 dan variabel $Z$ 
Etihad: Journal of Islamic Banking and Finance

Vol. 1, No. 2 Juli-Desember: 146-157

adalah 0,868. Nilai reliabilitas komposit masing-masing variabel lebih dari 0,7 yang mengindikasikan model telah memenuhi pengujian reliabilitas.

Model persamaan struktural yang dibentuk dari hasil yang koefisien inner model pada Tabel 4 sebagai berikut:

$$
\begin{aligned}
& \eta_{\text {loyalitas }}=0,127 \xi_{1}+0,347 \xi_{2}+0,389 \xi_{3}+3_{1} \\
& \eta_{\text {kepuasan }}=0,309 \xi_{1}+0,503 \xi_{2}+\xi_{2}
\end{aligned}
$$

dimana

$$
\begin{array}{ll}
\eta_{\text {loyalitas }} & : \text { Loyalitas nasabah } \\
\eta_{\text {kepuasan }} & : \text { kepuasan nasabah } \\
\xi_{1} & : \text { kemudahan } \\
\xi_{2} & : \text { kualitas pelayanan } \\
\xi_{3} & : \text { kepuasan nasabah } \\
\left\{_{1,2}\right. & : \text { Error model structural }
\end{array}
$$

Dari model persamaan struktural pada persamaan (1) yang terbentuk dan pengujian parameter model dapat dijelaskan sebagai berikut

a. Variabel kemudahan memiliki nilai pvalue 0,264>0,05 yang artinya variabel kemudahan tidak memiliki pengaruh pada loyalitas nasabah pengguna e-channel.

b. Variabel kualitas pelayanan memiliki nilai pvalue $0,003<0,05$ yang artinya variabel kualitas pelayanan memiliki pengaruh pada loyalitas nasabah pengguna e-channel. Koefisien parameter model sebesar 0,347 mengindikasikan bahwa pengaruh yang diberikan adalah pengaruh yang positif yang artinya semakin baik kualitas pelayanan yang diberikan maka semakin tinggi loyalitas nasabah pengguna e-channel.

c. Variabel kepuasan nasabah memiliki nilai pvalue $0,000<0,05$ yang artinya variabel kepuasan nasabah memiliki pengaruh pada loyalitas nasabah pengguna e-channel. Koefisien parameter model sebesar 0,389 mengindikasikan bahwa pengaruh yang diberikan adalah pengaruh yang positif yang artinya semakin tinggi kepuasan nasabah yang diberikan, maka semakin tinggi loyalitas nasabah pengguna e-channel.

Dari model persamaan struktural pada persamaan (2) yang terbentuk dan pengujian parameter model dapat dijelaskan sebagai berikut;

a. Variabel kemudahan memiliki nilai pvalue $0,00<0,05$ yang artinya variabel kemudahan memiliki pengaruh pada kepuasan nasabah pengguna e-channel. Koefisien parameter model sebesar 0,309 mengindikasikan bahwa pengaruh yang diberikan adalah pengaruh yang positif yang artinya semakin mudah penggunaan echannel, maka semakin tinggi kepuasan nasabah pengguna e-channel.

b. Variabel kualitas pelayanan memiliki nilai pvalue $0,00<0,05$ yang artinya variabel kualitas pelayanan memiliki pengaruh pada kepuasan nasabah pengguna $e$-channel. Koefisien parameter model sebesar 0,503 mengindikasikan bahwa pengaruh yang diberikan adalah pengaruh yang positif yang artinya semakin baik kualitas pelayanan yang diberikan, maka semakin tinggi kepuasan nasabah pengguna e-channel. 
Etihad: Journal of Islamic Banking and Finance

Vol. 1, No. 2 Juli-Desember: 146-157

Tabel 5. Specific Indirect Model

\begin{tabular}{ccc}
\hline & Original Sample (O) & $P$ Values \\
\hline$X_{1}->Z>Y$ & 0,12 & 0,015 \\
\hline$X_{2}->Z>Y$ & 0,195 & 0,001 \\
\hline
\end{tabular}

Dari hasil estimasi spesifikasi model tidak langsung pada Tabel 5 dapat dijelaskan sebagai berikut

a. Variabel kepuasan nasabah pengguna e-channel mampu memediasi pengaruh variabel kemudahan terhadap variabel loyalitas nasabah pengguna e-channel. Hal ini dapat dibuktikan dengan besarnya nilai pvalue 0,015<0,05.

b. Variabel kepuasan nasabah pengguna e-channel mampu memediasi pengaruh variabel kualitas pelayanan terhadap variabel loyalitas nasabah pengguna $e$-channel. Hal ini dapat dibuktikan dengan besarnya nilai pvalue 0,001<0,05.

Tabel 6. Koefisien Determinasi

\begin{tabular}{rrr}
\hline & R Square & \multicolumn{1}{c}{ R Square Adjusted } \\
\hline $\mathrm{Y}$ & 0,606 & 0,593 \\
\hline $\mathrm{Z}$ & 0,560 & 0,551 \\
\hline
\end{tabular}

Nilai $\mathrm{R}^{2}$ dari model struktural yang diperoleh adalah 0,606 yang mengindikasikan bahwa semua variabel kemudahan, kualitas pelayanan, dan kepuasan nasabah dapat memberi pengaruh pada loyalitas nasabah sebesar 60,6\%. Untuk kepuasan nasabah mampu dijelaskan oleh variabel kemudahan dan kualitas pelayanan sebesar $56,0 \%$.

\section{KESIMPULAN}

Hasil penelitian menunjukkan bahwa kemudahan tidak berpengaruh terhadap loyalitas nasabah akan tetapi kualitas pelayanan dan kepuasan nasabah berpengaruh terhadap loyalitas nasabah, kemudahan dan kualitas pelayanan berpengaruh terhadap kepuasan nasabah. Selain itu, kepuasan nasabah mampu memediasi pengaruh kemudahan terhadap loyalitas nasabah serta mampu memediasi pengaruh kualitas pelayanan terhadap loyalitas nasabah. Besarnya pengaruh yang diberikan variabel kemudahan, kualitas pelayanan, dan kepuasan nasabah pada loyalitas nasabah sebesar 60,6\%. Sedangkan besarnya pengaruh variabel kemudahan dan kualitas pelayanan terhadap kepuasan nasabah sebesar $56,0 \%$.

Berdasarkan hasil yang diperoleh pada penelitian ini harapannya BSI KCP Ponorogo dapat memberikan perhatian yang lebih pada kualitas pelayanan yang diberikan kepada nasabah dalam rangka mencapai tujuan dari BSI. Pihak BSI dapat memulai menyediakan kotak saran untuk memberikan kebebasan pada nasabah menunjukkan kekurangan dari pelayanan yang diberikan agar dapat diperbaiki dan nasabah merasa nyaman yang pada akhirnya nasabah menjadi puas dan loyal pada BSI. Selain meningkatkan kualitas pelayanan dapat pula dengan memberikan panduan penggunaan e-channel agar setiap nasabah mampu 
Etihad: Journal of Islamic Banking and Finance

Vol. 1, No. 2 Juli-Desember: 146-157

menggunakan e-channel dengan optimal. Pada penelitian selanjutnya dapat dilakukan penelitian dengan menggunakan variabel independent yang lain seperti motivasi, produk, maupun promosi.

\section{REFERENSI}

Aprilinda, P. (2019). Pengaruh Kualitas Pelayanan Kualitas Produk dan Promosi Terhadap Loyalitas Pelanggan Pada Kedai Kings Coffee Lippo Cikarang (Skripsi). Universitas Pelita Bangsa, Bekasi.

Basri, A. I. (2019). Pengaruh Kualitas Layanan Terhadap Kepuasan dan Loyalitas Nasabah Bank Pengguna E-Banking. Bisman (Bisnis dan Manajemen): The Journal of Business and Management, 2(1), 1-18.

Devy. (2020, September 29). Wawancara.

Fandi Tjiptono. (2002). Manajemen Jasa. Yogyakarta: Andi Offset.

Ghozali, I. (2014). SEM Metode Alternatif dengan menggunakan Partial Least Squares (PLS). Semarang: Badan Penerbit Universitas Diponegoro.

Ghozali, I. (2021). Partial least Squares Konsep, Teknik, dan Aplikasi Menggunakan Program SmartPLS 3.2.9 untuk Penelitian Empiris. Semarang: Badan Penerbit Universitas Diponegoro.

Idhom, A. M. (2021). Profil Direksi Bank Syariah Indonesia yang Resmi Berdiri Hari Ini. Diambil 30 November 2021, dari Tirto.id website: https://tirto.id/profil-direksi-bank-syariahindonesia-yang-resmi-berdiri-hari-ini-f9RP

Idrus, S. A. I. (2021). Kualitas Pelayanan dan Keputusan Pembelian: Konsep danTeori. Jakarta: Media Nusa Creative (MNC Publishing).

Istiqomawati, A. (2017). Pengaruh Dimensi Relationship Marketing Terhadap Kepuasan Dan Loyalitas Nasabah (Studi Kasus Pada BPR Argodana Pudak Payung Semarang). Jurnal Ekonomi dan Bisnis, 18(1), 28-39.

Izzah, D., \& Chasanah, U. (2020). Pengaruh Kualitas Pelayanan, Citra Merek, dan Harga terhadap Loyalitas dengan Kepuasan Konsumen sebagai Pemediasi pada Sinau Kopi PT. Abadi Bina Indonesia. (Skripsi). STIE Widya Wiwaha, Yogyakarta.

Kotler, P., \& Amstrong, G. (2012). Prinsip-Prinsip Pemasaran Jilid 1 Edisi 13. Jakarta: Erlangga. Kotler, P., \& Keller, K. L. (2009). Manajemen Pemasaran Jilid 1 Edisi 13. Jakarta: Erlangga.

Marconi, J. (1993). Beyond Branding. Chicago: Probus Publishing Company.

Mursyid, G. M. (2018). Pengaruh Promosi, Kualitas Pelayanan dan Harga Terhadap Loyalitas Konsumen (Studi Empiris Pada Pelanggan Foto Studio 26 Surakarta. (Skripsi). Universitas Muhammadiyah Surakarta, Surakarta.

Pradana, F. (2018). Pengaruh Manajemen Hubungan Pelanggan, Kualitas Pelayanan, Dan Kualitas Pengalaman Terhadap Loyalitas Pelanggan Dengan Kepuasan Pelanggan Sebagai Variabel Intervening Pada Nasabah Pt Fac Sekuritas Indonesia Di Yogyakarta. Jurnal Manajemen Bisnis, 9(2), 193-212. https://doi.org/10.18196/mb.9262

Priansa, D. J. (2017). Perilaku Konsumen Dalam Persaingan Bisnis Kontemporer. Bandung: ALFABETA.

Profil dan Produk Bank BRI Syariah. (2015). Diambil 30 November 2021, dari SyariahBank.com website: https://www.syariahbank.com/profil-dan-produk-bank-bri-syariah/

Santi, I. H., \& Erdani, B. (2021). TECHNOLOGY ACCEPTANCE MODEL (TAM). Penerbit NEM. 
Etihad: Journal of Islamic Banking and Finance

Vol. 1, No. 2 Juli-Desember: 146-157

Santi, I. H., \& Sudiasmo, F. (2020). PERCEIVED USEFULNESS DAN PERCEIVED EASE OF USE TERHADAP BEHAVIORAL INTENTION TO USE DAN ACTUAL USAGE PADA APLIKASI IDENTIFIKASI JENIS KULIT WAJAH. Surabaya: Jakad Media Publishing.

Sigit, K. N., \& Soliha, E. (2017). Kualitas Produk Dan Kualitas Layanan Terhadap Kepuasan Dan Loyalitas Nasabah. Jurnal Keuangan dan Perbankan, 21(1), 157-168.

Sola, K. I. (2017). Pengaruh harga, kualitas produk dan kualitas pelayanan terhadap loyalitas pelanggan (studi kasus pada Sakola Factory Outlet Jogja) (Skripsi, Sanata Dharma University). Sanata Dharma University, Yogyakarta. Diambil dari https://repository.usd.ac.id/22915/

Sujarweni, V. W. (2015). Metodologi Penelitian Bisnis dan Ekonomi. Yogyakarta: Pustaka Baru Press.

Susanti, E., \& Parera, N. O. (2021). LOYALITAS NASABAH DARI KEMUDAHAN PENGGUNAAN MOBILE BANKING. International Journal of Digital Entrepreneurship and Business, 2(1), 39-48. https://doi.org/10.52238/ideb.v2i1.37

Widarjono, A. (2015). Analisis Multivariat Terapan Dengan Program SPSS, AMOS, dan SMARTPLS (2 ed.). Yogyakarta: UPP STIM YKPN.

Widoyoko, E. P. (2017). Teknik Penyusunan Instrumen Penelitian. Yogyakarta: Pustaka Pelajar.

Wijaya, H., Beik, I. S., \& Sartono, B. (2017). Pengaruh kualitas layanan perbankan terhadap kepuasan dan loyalitas nasabah bank syariah xyz di jakarta. Jurnal Aplikasi Bisnis dan Manajemen (JABM), 3(3), 417-417. 